\title{
Overseas Travel And Tourism - Quarter 2 2011
}

\section{Coverage: UK}

Date: 13 October 2011

Geographical Area: Region

Theme: People and Places

\section{Latest Trends}

\section{International travel up in 2011}

For the second quarter running, quarter 2 saw an increase in visits to and from the UK compared with the same period in 2010. It should be noted, however, that at least part of the increase in quarter 2 is believed to be due to the disruption to international travel in 2010 caused by volcanic ash.

\section{Introduction}

This report contains estimates of completed international visits to and from the UK and earnings and expenditure associated with these visits. The estimates are derived from the International Passenger Survey (IPS) conducted by ONS at all major air and Eurostar ports in the UK as well as on sea and Eurotunnel routes into and out of the UK.

Parts of the report refer to countries visited abroad. It should be noted that if a UK resident visited more than one country on a trip abroad, the country recorded as visited in this publication is the country that was visited for the longest period.

\section{Accuracy of IPS estimates}

The estimates produced from the IPS are subject to sampling errors that result because not every traveller to or from the UK is interviewed on the survey. Sampling errors are determined both by the sample design and by the sample size - generally speaking, the larger the sample supporting a particular estimate, the proportionately smaller is its sampling error. The survey sample size is approximately 70,000 per quarter.

Table A shows the sampling errors for the main quarterly estimates of the total number of visits, nights and expenditure for both overseas residents visiting the UK and UK residents going abroad. Both standard errors and the 95 per cent confidence intervals are quoted, the latter representing 
the interval into which there are 19 chances out of 20 that the true figure (had all travellers been surveyed) would lie. If, for example, the relative 95 per cent confidence interval relating to an estimate of 10,000 was $5.0 \%$ there would be 19 chances out of 20 that the true figure (if all travellers had been surveyed) would lie in the range 9,500 to 10,500 .

IPS sampling errors for Quarter 22011 estimates

\begin{tabular}{lll} 
& Absolute & Relative \\
\cline { 2 - 3 } Standard & $95 \%$ & $95 \%$ \\
\cline { 2 - 3 } error & confidence & confidence \\
\hline
\end{tabular}

Overseas visitors to the UK

Number of visits (1000s)

155

305

$3.7 \%$

Number of visitor-nights (1000s)

1,545

3,037

$5.2 \%$

Total earnings ( $£$ million)

107

210

$4.7 \%$

UK residents going abroad

Number of visits (1000s)

184

361

$2.4 \%$

Number of visitor-nights (1000s)

2,519

4,952

$3.3 \%$

Total expenditure ( $£$ million)

118

231

$2.9 \%$

\section{Download table}

XLS XLS format

(22.5 Kb)

Further detail on the confidence intervals of data from the IPS and their interpretation can be obtained from the IPS Branch of ONS.

\section{Visits to the UK by overseas residents}

A total of 8.3 million visits to the UK were made in quarter 22011 , an increase of 7.3 per cent over the same period in 2010. This is the fourth consecutive quarter in which the number of visits to the UK by overseas residents has grown. 


\section{Change from a year earlier in visits to the UK from overseas residents}

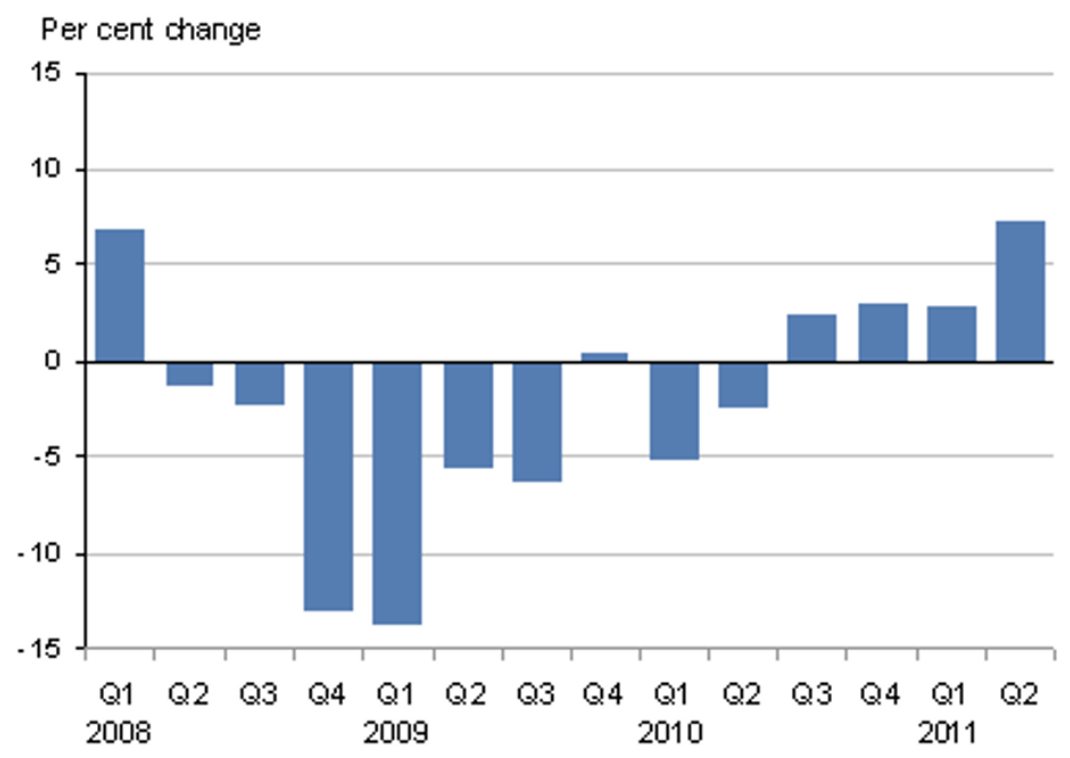

\section{Download chart}

\section{XLS XLS format}

$(13.5 \mathrm{~Kb})$

Visits from residents of North America increased by 11.6 per cent in the quarter, from Europe by 4.3 per cent and from other countries by 20.5 per cent.

The purpose of visit which showed the strongest increase in quarter 2 was holidays, up 9.3 per cent from 3.3 million to 3.6 million. This represents a return to growth following stability in the previous quarter. Inclusive tours accounted for 822 thousand of the 3.6 million holidays in quarter 2. Such visits are continuing to show growth, up 10.5 per cent year to date.

The number of business visits to the UK continued to rise following a sharp fall in 2009. In the first two quarters of 2011 there have been a total of 3.7 million business visits, compared with 3.4 million in the same period in 2010, but down from 4.4 million in 2008.

Visits to London saw a strong quarterly rise, from 3.6 million in quarter 2 2010, to 4.0 million. Visits to the rest of England (up from 3.4 million to 3.6 million) and to Wales also grew.

An estimated total of 58.1 million nights were spent in the UK by overseas residents during quarter 2. This represents an increase of 8.7 per cent compared with 2010. Earnings stood at £4.5 billion, up 3.4 per cent from a year earlier.

\section{Visits abroad by UK residents}

UK residents completed a total of 15.5 million visits abroad in quarter 22011 , up from 14.6 million in the same period in 2010. This represents an increase of 6.3 per cent. 


\section{Change from a year earlier in visits abroad by UK residents}

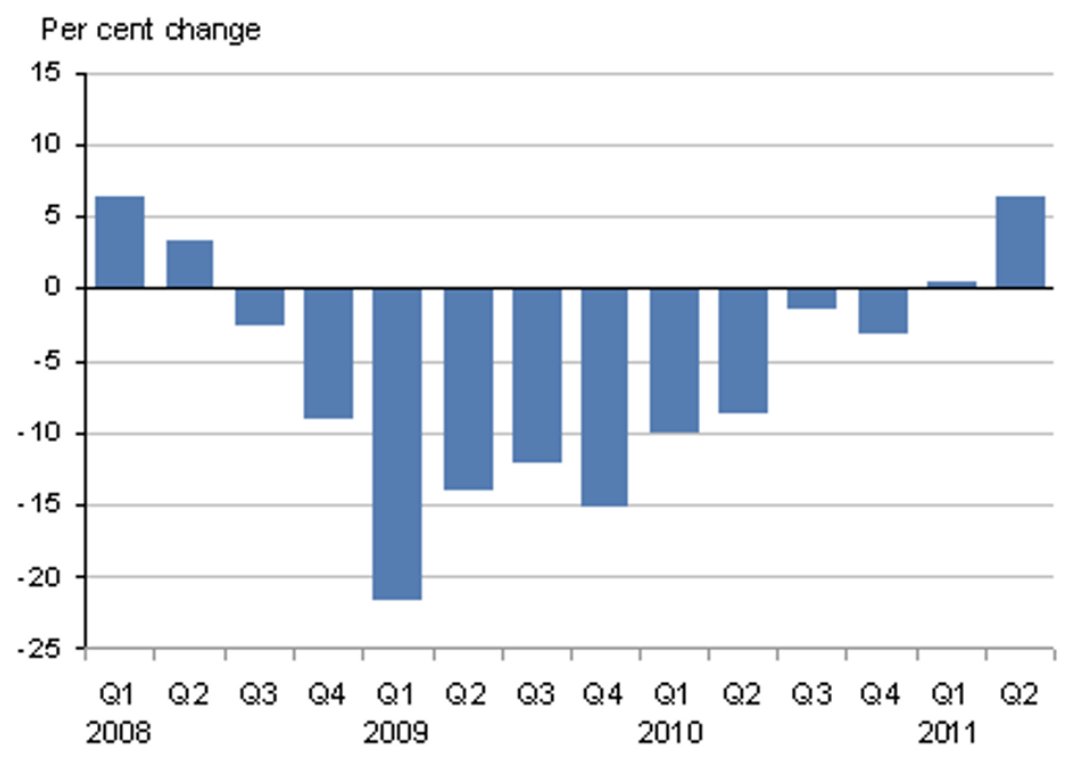

\section{Download chart}

\section{XLS XLS format}

$(13.5 \mathrm{~Kb})$

This is the second consecutive quarter in which visits abroad have shown some growth following falls in the previous ten quarters. However, the total of 15.5 million visits is 3 million lower than the figure recorded in quarter 2 2008, near the start of the global economic crisis.

Visits to both Europe and North America grew in quarter 2. The 12.3 million visits to Europe represented an increase of 0.8 million from a year ago and the 1.0 million visits to North America was an increase of nearly 0.1 million. There appear to be signs of a return to visiting North America. In the period since October 2010 the total number of visits to North America has grown by nearly 10 per cent versus a year earlier.

Visits to other countries remained broadly unchanged this quarter, and a sharp fall in visits to North Africa has occurred since the start of the year.

The majority of growth in total visits abroad in quarter 2 was accounted for by holidays. They grew from 9.5 million in quarter 22010 to 10.4 million. Holidays to Europe rose from 7.7 million to 8.5 million. Inclusive tours grew from 3.8 million to 4.2 million.

Although UK residents have increased their numbers of visits abroad this year, their spend on these visits has fallen. This may be impacted by inflated spending in quarter 22010 in response to travel disruptions. The total number of nights spent abroad in quarter 22011 was 151.0 million, up just 0.3 per cent compared with 2010.

\section{Contact Details}

\section{General IPS queries \& requests}


For general questions about IPS and requests for ad hoc data analysis (a service governed by the

ONS Income and Charging policy):

Tel: Data Advice Relations Team: 01633455678

Email: socialsurveys@ons.gsi.gov.uk

Other customer enquiries

Media enquiries

ONS Customer Contact Centre

Tel: 08456013034

International: +44 (0)8456013034

Tel: 08456041858

\section{Statistical contact}

For information about the content of this publication

Tel: 01633455277

Email: socialsurveys@ons.gsi.gov.uk

\section{Copyright and reproduction}

OCrown copyright 2011

You may re-use this information (not including logos) free of charge in any format or medium, under the terms of the Open Government Licence.

To view this licence, go to: http://www.nationalarchives.gov.uk/doc/open-government-licence/ or write to the Information Policy Team, The National Archives, Kew, London TW9 4DU Email: psi@nationalarchives.gsi.gov.uk

\section{Background Notes: Publication tables}

\section{Notes to tables}

Table 5: Overseas earnings and expenditure at constant (1995) prices - includes estimates for the Channel Islands.

Table 7: Nights spent abroad by UK residents includes cruises allocated to 'Other Areas' (see note 29 under 'sample methodology'). 
Table 11: Spending by overseas residents by area and purpose of visit. See notes 10, 11 and 12 under 'Definitions'.

\section{Exclusions}

Trippers who cross the Channel or the North Sea but do not alight from the boat.

Migrants and persons travelling overseas to take up prearranged employment, together with military/ diplomatic personnel, merchant seamen and airline personnel on duty.

Overseas residents passing through the UK en route to other destinations (often known as transit passengers) but who do not stay overnight (however any spending whilst here is included in the figures for earnings).

\section{Symbols}

$\mathrm{P}=$ Provisional

$\mathrm{R}=$ Revised

- = Not available or no sample

$0=$ visits less than 500 or spending less than $£ 50,000$

VFR $=$ Visiting friends or relatives

Please Note Due to rounding, constituent items in the tables may not add exactly to totals

\section{Background Notes: Definitions}

\section{Definitions}

1. The figures relate to the number of completed visits, not the number of visitors. Anyone entering or leaving more than once in the same period is counted on each visit. The count of visits relates to UK residents returning to this country and to overseas residents leaving it.

2. Day-visits (that is trips that do not involve an overnight stay) abroad by UK residents as well as day trips to the UK by overseas residents are included in the figures for visits and expenditure. Details of such visits are shown separately in Tables 8-11 and 19-22 under the heading 'day visits'.Please note they do not cover day visits to or from the Irish Republic across the land border, although they are included in total visits. For overseas residents in transit through the UK see note 9.

3. An overseas visitor means a person who, being permanently resident in a country outside the United Kingdom, visits the UK for a period of less than 12 months. UK citizens resident overseas for 12 months or more coming home on leave are included in this category. Visits abroad are visits for a period of less than 12 months by people permanently resident in the UK (who may be of foreign nationality. 
4. When a resident of the UK has visited more than one country the entire visit, expenditure and stay are allocated to the country stayed in for the longest time.

5. Visits for miscellaneous purposes include those for study; to attend sporting events; for shopping; health; religious; or for other purposes; together with visits for more than one purpose when none predominates (for example visits both on business and on holiday). Overseas visitors staying overnight in the UK en route to other destinations are also included in miscellaneous purposes.

6. Estimates relating to tourist flows across the land border between the Irish Republic and Northern Ireland are, for convenience, included in the figures for sea. Where not shown separately, flows through the Channel Tunnel are also included under the figures for sea.

7. Regional Analysis (Table 13). The information relating to visitors using the land border from the Irish Republic is not collected and so is excluded from the table. Also excluded (except from the 'Total' section) are all visits that did not include an overnight stay in the UK. Visits by overseas residents to Northern Ireland although included in the 'total' column are not separately analysed. More than one region can be visited by an individual whilst in the United Kingdom and so the total of the visits to all regions will therefore sometimes be greater than the total number of visits to the UK.

8. Adjustments are made to the reported cost of an inclusive tour so that only the amount earned by the country of visit (for example accommodation costs, car hire, etc.) is included. This estimate is then added to an individual's spending to give the total spending in the country of visit (see also note 9).

9. Length of stay for UK residents cover the time spent, including the journey outside the UK, whilst for overseas residents it refers to the time spent within the UK.

10. Earnings and expenditure figures cover the same categories of travellers as do the number of visits, except that in addition the earnings figures include the expenditure by same day transit passengers, and the foreign exchange earnings and expenditure due to travel relating to the Channel Islands. They exclude payments for air, sea and rail travel to and from the UK. For any traveller on an inclusive tour an estimate of the return fare is deducted from the total tour price.

11. Earnings do not include the personal export of cars that have been purchased in the United Kingdom by overseas residents. Similarly spending excludes the personal import of cars by UK residents.

12. An estimate for purchases by overseas visitors at airport duty free shops is included in the figures for earnings. Such purchases on British carriers are still excluded.

\section{Background Notes: Geographical Areas}

\section{Geographical areas:}

1. North America: Canada (including Greenland and St Pierre at Miquelon), USA (including Puerto Rico and US Virgin Islands).

2. Europe: All countries listed under EU27 plus other central and eastern Europe; North Cyprus; Gibraltar; Iceland (including Faroe Islands); Norway; Switzerland (including Liechtenstein); Turkey; the former USSR; and the states of former Yugoslavia.

3. EU15: Austria; Belgium; Denmark; France (including Monaco); Finland; Germany; Greece; Irish Republic; Italy (including San Marino and Vatican City); Luxembourg; Netherlands; Portugal (including Azores and Madeira); Spain (including Canary Islands; and the Balearic Islands and Andorra); and Sweden. 
4. EU25 As for EU15 plus Cyprus (see * below); Czech Republic; Estonia; Hungary; Latvia; Lithuania; Malta; Poland; Slovakia; and Slovenia. Only the south of Cyprus is a member of the EU, but the IPS is unable to separate North and South Cyprus for the period before May 2004, and so all of Cyprus is included in the EU25 section until May 2004. From May 2004 only southern Cyprus is included in the EU25 figures. Where Cyprus is shown separately in a table, the figures relate to the whole island.

5. EU27: As for EU25 plus Bulgaria and Romania.

6. North Africa: Algeria, Libya, Morocco and Sudan.

7. Other Middle East: Bahrain; Iran; Iraq; Jordan; Kuwait; Lebanon; Oman; Qatar; Saudi Arabia; Syria; and the Yemen.

8. Central and South America: Argentina; Belize; Bolivia; British Antarctica; Brazil; Chile; Colombia; Costa Rica; Ecuador; El Salvador; the Falkland Islands; French Guiana; Guatemala; Guyana; Honduras; Nicaragua; Panama (including Canal Zone); Paraguay; Peru; Surinam; Uruguay; and Venezuela.

9. Other Caribbean: Antigua; Bahamas; Bermuda; British Virgin Islands; Cayman Islands; Cuba; Dominica; the Dominican Republic; Grenada; Haiti; Martinique; Montserrat; St Kitts-NevisAnguilla; St. Lucia; St. Vincent and the Grenadines; Trinidad and Tobago; Turks and the Caicos Islands.

\section{Background Notes: Sample Methodology}

\section{Sample Methodology}

1. The International Passenger Survey (IPS) produces estimates that are based on interviews with a stratified random sample of passengers entering and leaving the UK on the principle air, tunnel and sea routes. The main features of the stratification are: mode of transport (that is air, tunnel or sea), port and time of day.

2. The frequency of sampling within each stratum depends mainly on the variation of tourist expenditure and on the volume of migrants, for which the survey is also used to collect statistics. Travellers passing through passport control are randomly selected for interview and in all some 316,000 interviews were conducted in 2010. Only interviews carried out at the end of a visit are used to generate estimates of expenditure and stay. Of these interviews around 52,000 provided the published information on foreign visitors to the UK and around 67,000 were used for the estimate of UK residents travelling abroad. The interviews were conducted on a purely voluntary and anonymous basis.

3. Despite the introduction in April 1999 of interviewing on air and sea routes to and from the Irish Republic (see notes 4 and 5 of the 'Background Notes: Accuracy of the results' section) the results from the IPS are still supplemented with estimates of travel between UK and the Irish Republic over the land border where no IPS interviewing takes place. Estimates for travel by land are based on information provided by the Central Statistics Office of the Irish Republic. Estimates of earnings and expenditure are also supplemented with figures from the Economic Advisor's Office of the States of Jersey, who provide information about the Channel Islands.

4. About 95 per cent of passengers entering and leaving the UK (excluding those travelling by land to and from the Irish Republic) travel on routes covered by the survey. The remainder are either passengers travelling at night when interviewing is suspended, or on those routes too small in volume to be covered. For those passengers, estimates are made and input into the main results of the survey. 
5. At the major airports a sample of half days is taken and a fixed proportion of passengers are interviewed, whilst the smaller airports are sampled occasionally with the number of visits depending on the number of international passengers.

6. On the sea routes either particular cross-channel sailings are sampled and a fixed proportion of passengers interviewed on board, or a sample of days is taken and the passengers interviewed on the quay side.

7. In all, approximately 316,000 travellers (0.2 per cent of the total travellers) were interviewed in 2010; this proportion varies from port to port.

8. UK residents who left a cruise boat at a foreign port and returned home on a scheduled air or sea service (e.g. fly-cruises) are included in the IPS. Information on the number of passengers on cruises finishing in the UK is estimated in terms of the number of visits, length of stay and expenditure. These estimates are added to the cruise data collected from the IPS and included under the headings for 'other areas', 'holiday', and 'sea'. In 2010 a review took place of the methodology used to estimate the number of such visits. This review has led to more accurate methodology for estimating these visits and has resulted in an annual increase from the approximately 20 thousand to 200 thousand of such visits. The new estimates have been included in both publication and Travel Trends 2010 in late July 2011.

9. A complex weighting procedure is used in the survey results taking account of passengers movement statistics produced by the BAA plc and the Civil Aviation Authority for air traffic by the Department for Transport for sea traffic. For Heathrow, Gatwick and Manchester allowances are made for passengers in transit who do not pass through passport control and hence do not cross the IPS counting line.

\section{Background Notes: Accuracy of the results}

\section{Accuracy of the results}

1. As the information is collected by a sample survey, the estimates of the number of visits, length of stay and expenditure are subject to a sampling error. Generally speaking, the larger the sample supporting a particular estimate, the smaller its sampling error. However, as the intensity of the sampling varies at each port, figures of a similar magnitude will not necessarily have the same percentage sampling error.

2. The IPS has a clustered sample design. The full effects of this complex sample design upon each of the main estimates is calculated, and it is these calculated 'complex' sampling errors which are quoted.

3. The sampling errors of IPS estimates are given in terms of an interval in to which there are 19 chances out of 20 that the true figure will fall. This is known as a 95 per cent confidence interval; the estimate plus or minus the percentage quoted gives the appropriate interval.

4. The estimate of the total number of overseas residents' visits to the UK (excluding land based visits from the Irish Republic) in 2010 as a whole had a 95 per cent confidence interval of +2.0 per cent. Total visitor-nights and total earnings for the year had 95 per cent confidence intervals of +2.6 per cent and +3.4 per cent respectively.

5. The estimate of the total number of UK residents' visits abroad (excluding land based visits to the Irish Republic) in 2009 as a whole had a 95 per cent confidence interval of +1.2 per cent. Total visitor-nights and total expenditure for the year had 95 per cent confidence interval rates of +1.8 per cent and +1.8 per cent respectively. 


\section{Background Notes: Important change in IPS sampling}

\section{Important change in IPS sampling}

1. The IPS commenced interviewing to and from the Irish Republic in April 1999. Results for 1999 shown in this edition have been revised from previously published estimates following the use and analysis of records produced by interviews conducted on these new routes. The inclusion of the Irish routes in the IPS sample creates a discontinuity in the results and so additional care must be taken when making time series analyses of the data or when comparing the results with previously published data.

2. The inclusion of the Irish routes sample does not simply adjust the numbers of visits made to the UK by residents to the Irish Republic and to the Irish Republic by UK residents. The new sample shows that many trips are made on these routes by residents of regions other than the UK or the Irish Republic, which means that estimates of visits and spending for some countries other than the Irish Republic have also been subject to revision.

3. Traffic at all airports and seaports is monitored regularly to assess if they should be included in the IPS sample. As a consequence Liverpool and Prestwick airports were introduced into the sample at the beginning of 2005. Between 2000 and 2004, traffic through Liverpool had quadrupled to 'over two and a half million' international passengers, while at Prestwick there was a fivefold increase to nearly 'one and a half million' passengers over the same period. The inclusion of these ports in the IPS sample were shown to cause a discontinuity in regional results and methodology was modified to account for this. Similarly in early 2008 each of Doncaster, Bournemouth, Southampton and Heathrow Terminal 5 were added to the sample and in 2009 Aberdeen and Belfast International airports were added.

\section{Background Notes: Changes to the IPS in 2009}

\section{Changes to IPS in 2009}

1. From January 2009 certain elements of the IPS have been revised to address recommendations put forward by the Interdepartmental Task Force on Migration Statistics, 2006. The changes involve revision to sample design, weighting and imputation methodology. These changes resulted in some discontinuity in estimates. An analysis was conducted and published in 2009. More details are available from the IPS team.

2. The model used to produce seasonal adjustment estimates is reviewed approximately every two years. A review was conducted in late 2009 and the new model was used for the first time to produce the seasonally adjusted estimates used in the December 2009 'Statistical Bulletin' publication. Details of the seasonal adjustment model can be obtained from the IPS team using the contact details attached. 


\section{Background Notes: Further Statistics \& Other Analyses}

\section{IPS data files}

IPS data for the years 1993 onwards are available online from www.ons.gov.uk. Travelpac is a free and simple to use dataset for those wishing to make further analyses of IPS data. It contains files provided in Excel and SPSS formats. More details can be found at Travelpac.

\section{Monthly figures of Overseas Travel and Tourism}

These are published in the Overseas Travel and Tourism Statistical Bulletin available from

Office for National Statistics, Government Buildings, Cardiff Road, Newport, NP10 8XG.

Telephone: 01633455286 or from the ONS website at www.ons.gov.uk.

\section{Further statistics}

More detailed statistics covering 2002 to 2010 may be found in the 2010 annual report, Travel Trends which is produced by the ONS. A copy can be downloaded from www.ons.gov.uk/ons/rel/ott/ travel-trends/2010/travel-trends---2010.pdf.

\section{Other analyses}

All general enquiries about the IPS should be directed to the Office for National Statistics at the address shown above. Individual contact records may be purchased and can be supplied on CDROM. It is possible to commission more detailed analyses of the IPS data from marketing agents appointed by ONS.

The marketing agents are:

\section{MDS Transmodal}

5-6 Hunters Walk, Canal Street, Chester, CH1 4EB

Telephone 01244348301 Fax: 01244348471 Email: enquiries @ mdst.co.uk Web: www.mdst.co.uk

\section{IRN Research}

Concorde House, Trinity Park, Solihull, Birmingham, B37 7UQ

Telephone: 01216355210 Fax: 01216355211 Email: info @irn-research.com Web: www.irnresearch.com 


\section{Background Notes: The main analysis variables on the IPS database}

The full IPS dataset contains over 110 variables. These include variables containing answers to the questions asked in the interview and other that are derived from those answers. Some variables are simply indicators to help identify the quality of data or to show where data have been imputed, and to what degree. The most widely used variables for general analyses are described below:

\section{Year $^{1}$}

The year of the interview is recorded as a four-digit number.

\section{Quarter $^{1}$}

The four quarters of the calendar year are recorded as a single digit

\section{Month}

The month of interview is recorded as two digits from $01-12$.

\section{Flow ${ }^{1}$}

Flow describes the direction of travel and the basic residence of traveller. Flow is differentiated further according to whether the contact travelled by a) air, or b) by sea or Channel Tunnel. This gives eight categories of flow these being:

\# arrivals by UK residents (air, or sea/tunnel);

\# departures by UK residents (air, or sea/tunnel);

\# arrivals by overseas residents (air, or sea/tunnel);

\# departures by overseas residents (air, or sea/tunnel).

\section{Weight ${ }^{1}$}

The number of trips represented by each contact is given by the weight variable. The total number of trips can therefore be calculated by summing the weights' values of the contacts.

\section{Nationality}

The nationality of the contact is recorded for all contacts

\section{Country visited ${ }^{1}$}

The main country of visit (or country stayed in longest) by UK residents is recorded for arrivals and departures.

\section{Residence $^{1}$}


The country of residence of overseas residents is recorded for both arrivals and departures.

\section{Town of residence}

The town or area of residence is recorded for UK residents for arrivals

\section{States of residence}

Each year, the state or area within a country is recorded for overseas residents in addition to their country of residence. This detail is limited to four countries each year which are changed annually. In 2007 the countries are Canada, Germany, the Irish Republic and Japan.

\section{Purpose of visit ${ }^{1}$}

A single main purpose of visit is recorded for UK residents' arrivals and Overseas residents' departures. Prior to 2007 it was available for all contacts

\section{Stay ${ }^{1}$}

The length of stay of the visit is recorded in nights. This is only available for overseas residents' departures and UK residents' arrivals.

\section{Expenditure $^{1}$}

The amount of money spent on the trip (excluding fares) is recorded in $£$ sterling and is available for overseas residents' departures and UK residents' arrivals.

\section{UK port}

The UK port is the airport, or the sea/tunnel port or route where the interview was conducted

\section{First port}

This is the overseas port to which the contact is travelling directly (or travelled directly from). If the person does not change plane during the trip, 'First port' is also the final destination (for departures) or where the visit started from (for arrivals)

\section{Second port}

If 'First port' is a port where the contact changed planes, 'Second port' then records the final destination (for departures) or the place where the visit started from (for arrivals). It is otherwise left blank.

\section{Flight origin/destination}


This is an overseas airport which is either the final destination or the flight being taken (for air departures) or where the flight originated from (for air arrivals). This is not necessarily the same port at which the contact boarded or left the flight

\section{Mileage travelled}

The distance travelled is computed in miles from the geographical locations of the ports recorded. The distances represent the sea level (or 'great circle') distances covered. Three distances are calculated:

\# From the 'UK port' to 'First port' (for all air contacts).

\# From 'First port' to 'Second port' (if a second port is recorded)

\# From 'Second port' to 'UK port' (if a second port is recorded)

\section{Carrier}

This is the air company or shipping line used on the leg of the journey between the 'UK port' and 'First port'. However the carrier used between 'First port' and 'Second port' is not recorded.

\section{Class of travel}

Has been dropped from the IPS in 2007.

\section{Type of flight}

The type of flight e.g. scheduled or charter (air records only).

\section{Fare}

The single fare in $£$ sterling is recorded for UK residents' arrivals only. Prior to 2007 it was recorded on UK residents' departures

\section{Vehicle type}

The type of vehicle taken on board ship or train is recorded. If no vehicle is used or cannot be identified, the contact is recorded as being a foot passenger.

\section{Number in vehicle}

This is the number of people travelling in the vehicle recorded above.

\section{Age ${ }^{1}$}

The age group of the contact is asked and recorded for all UK residents' arrivals and Overseas residents' departures. Prior to 2007 it was available for all contacts

\section{Gender ${ }^{1}$}


Sex is recorded for all UK residents' arrivals and Overseas residents' departures. Prior to 2007 it was available for all contacts

\section{Towns 1 - 9}

For overseas residents' departures only, up to five towns in which the contact has spent at least one night are recorded.

\section{Stay 1 - 9}

The number of nights spent in 'Towns 1 - 9' are recorded.

\section{Spend 1 - 9}

Expenditure while in 'Towns 1 - 9' is not collected but it is imputed based on total expenditure, length of stay and area of visit.

\section{Package ${ }^{1}$}

This identifies whether the contact travelled as part of an inclusive tour package or travelled independently.

The above list is not exhaustive and excludes variables based on questions not asked regularly on the IPS. Variables regarding data quality are also not included.

${ }^{1}$ Information based on these variables is included in the Travelpac datasets. 